Supplement of Nat. Hazards Earth Syst. Sci., 21, 977-993, 2021

https://doi.org/10.5194/nhess-21-977-2021-supplement

(C) Author(s) 2021. CC BY 4.0 License.

(c) (i)

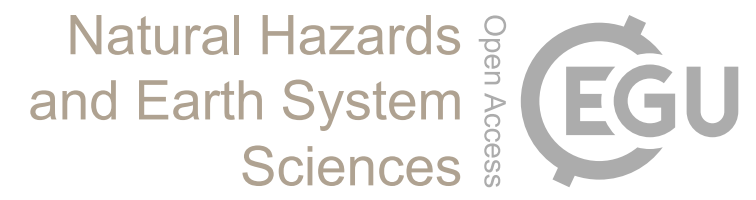

Supplement of

\title{
Evolution of surface deformation related to salt-extraction-caused sinkholes in Solotvyno (Ukraine) revealed by Sentinel-1 radar interferometry
}

Eszter Szúcs et al.

Correspondence to: Eszter Szúcs (Szucs.Eszter@csfk.mta.hu)

The copyright of individual parts of the supplement might differ from the article licence. 


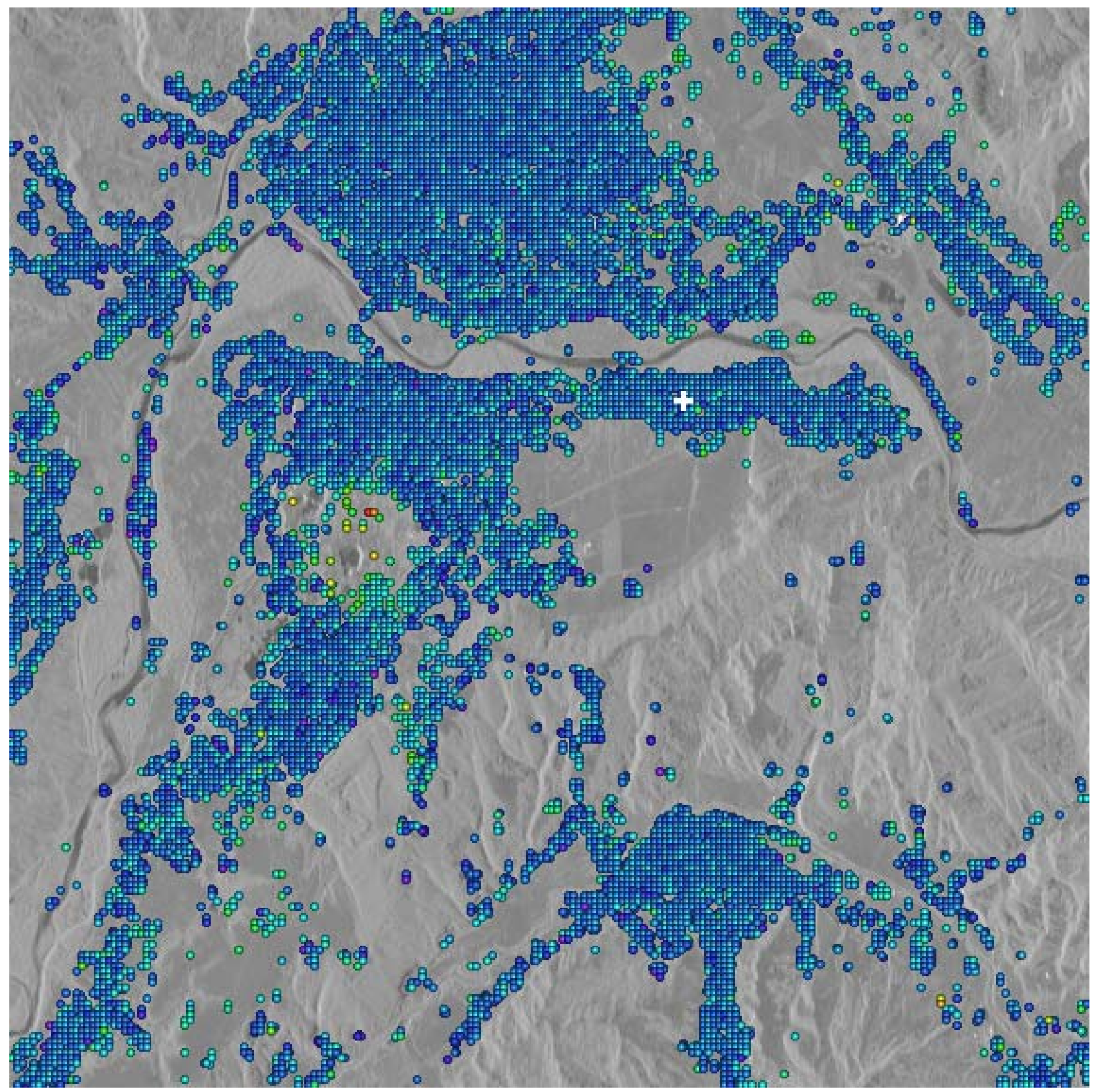

S1. LoS linear deformation rate from ascending Sentinel-1 scenes (track 29) in radar geometry, white cross shows non-deforming reference area. Same colorscale as Fig. 6. Contains modified Copernicus Sentinel data [2014-2019] 


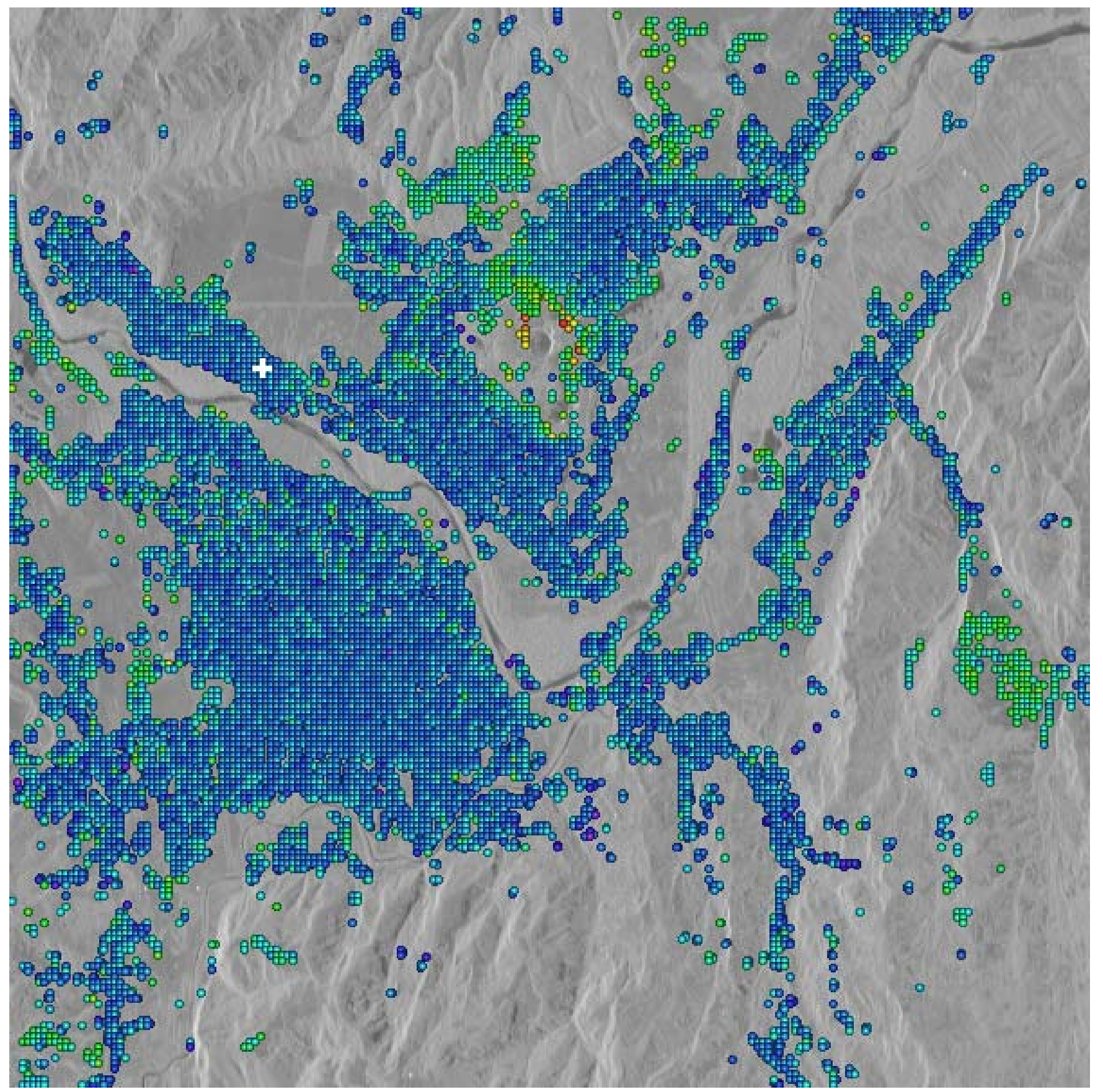

S2. LoS linear deformation rate in radar geometry determined from Sentinel-1 data of track 80 (descending pass), white cross shows non-deforming reference area. Same colorscale as Fig. 7. Contains modified Copernicus Sentinel data [2014-2019] 